\title{
TRANSFUSION OF LEUKOCYTES LABELED WITH RADIOACTIVE PHOSPHORUS
}

\author{
BY AUSTIN S. WEISBERGER, ROBERT W. HEINLE, JOHN P. STORAASLI, AND \\ RICHARD HANNAH
}

\author{
(From the Departments of Medicine and Radiology, Lakeside Hospital, and the School of \\ Medicine, Western Reserve University, Cleveland)
}

(Received for publication September 23, 1949)

Mechanisms involved in the failure to raise the white blood cell count by transfusion remain unknown. Previous studies (1) on the effect of transfusion of concentrated suspensions of leukocytes obtained from the peritoneal cavity of rabbits have confirmed the clinical observation that the white blood cell count cannot be effectively increased by transfusion. When concentrated suspensions of leukocytes were transfused into the venous system of the same rabbit from which they had been obtained or into other rabbits, not only was there no increase in the leukocyte count over a period of several hours, but a severe leukopenia developed in nearly every animal. In over half the rabbits a subsequent marked leukocytosis developed in four to six hours. This investigation was undertaken to study the disappearance of leukocytes from the circulating blood by determining the radioactivity in various tissues following the transfusion of leukocytes labeled with $\mathrm{P}^{\mathbf{3}}$.

\section{METHODS}

Leukocytes labeled with radioactive phosphorus were obtained by injecting a rabbit with approximately 1.0 millicurie of $\mathbf{P}^{32}$ intravenously prior to stimulating the production of leukocytes in the rabbit's peritoneum. Two to seven days after injecting the radioactive phosphorus, leukocytes were obtained from the rabbit's peritoneal cavity by a modification of the method of Mudd and coworkers (2). Three hundred to $500 \mathrm{ml}$. of physiologic saline were injected intraperitoneally in the evening and a similar amount about 15 hours later. Overdistension of the abdomen is poorly tolerated by the rabbits and may cause respiratory embarrassment and death. Four hours after the second injection of physiologic saline the peritoneal fluid was removed through a 16 gauge needle using $5 \mathrm{mg}$. of heparin as an anticoagulant. This fluid was centrifuged at a speed of about 500-1000 R.P.M. for five minutes and the sediment resuspended in Tyrode's solution so that the final concentration of cells was approximately 50,000 cells per cmm.

The leukocytes prepared in this manner stained normally with Wright's stain, exhibited ameboid activity, were actively phagocytic for staphylococci and took up supravital stain (Janus green and neutral red). Approximately $90 \%$ of the cells were segmented and unsegmented neutrophils.

The radioactive phosphorus was firmly bound within the cell, presumably in the nuclear nucleoprotein. In order to demonstrate this, samples of the leukocyte suspension were subjected to repeated washing with Tyrode's solution. Only negligible amounts of radioactivity could be removed by this procedure (Table I), indicating the chemically bound nature of the $\mathrm{P}^{32}$ in these cells.

TABLE I

Radioactivity in washing of leukocytes labeled with $\mathrm{P}$

$\begin{array}{llr} & \text { Amount } & \begin{array}{r}\text { Geiger } \\ \text { counts } \\ \text { per min. }\end{array} \\ \text { Concentrated cell suspension } & 1.0 \mathrm{ml} . & 1403 \\ \text { Fluid from 1st wash. } & 1.0 \mathrm{ml} . & 20 \\ \text { Fluid from 2nd wash. } & 1.0 \mathrm{ml} . & 15 \\ \text { Fluid from 3rd wash. } & 1.0 \mathrm{ml} . & 15\end{array}$

Of the concentrated white cell suspension, $1.0 \mathrm{ml}$. was ashed and the radioactivity determined with a GeigerMueller counter. 1 The total amount of radioactivity recovered in the leukocytes used for tracer studies ranged from $1.0 \%$ to $6.0 \%$ of the total radioactivity originally injected into the rabbit from which the cells were obtained. This was equivalent to approximately 10 to 60 microcuries and was usually between 20 and 40 microcuries.

The fate of the transfused white cells was studied by determining the radioactivity in various tissues following the injection of the radioactive leukocytes. Ten to $15.0 \mathrm{ml}$. of the leukocyte suspension containing approximately 50,000 cells per $\mathrm{cmm}$. were used for transfusion. One group of animals was sacrificed in $30 \mathrm{~min}$ utes and another in four to six hours. The distribution of

1 Calculations:

$(\mathrm{C} / \mathrm{M}$ in $1.0 \mathrm{ml}$. of $\mathrm{WBC}) \times$ volume of $\mathrm{WBC} \times 100$ (C/M of standard) $X$ dilution of standard

- Per cent of radioactivity present in white cell suspension.

$\mathbf{C} / \mathbf{M}=$ Counts per minute on Geiger-Mueller counter. The standard was taken from the radioactive phosphorus originally used to inject the rabbit so that no correction was necessary for rate of decay or geometry of the counting system. 
TABLE II

Distribution of radioactivity in tissues 30 minutes following the intravenous injection of 100 microcuries of inorganic radioactioe phosphorus

\begin{tabular}{c|c|c|c|c|c|c|c|c}
\hline \hline \multirow{2}{*}{$\begin{array}{c}\text { Rabbit } \\
\text { number }\end{array}$} & \multicolumn{2}{|c|}{ Lung } & \multicolumn{2}{c|}{ Liver } & \multicolumn{2}{c|}{ Spleen } & \multicolumn{2}{c}{ Kidney } \\
\cline { 2 - 9 } & $\% / \mathrm{Gm}$. & Tot. \% & $\% / \mathrm{Gm}$. & Tot. \% & $\% / \mathrm{Gm}$. & Tot. \% & $\% / \mathrm{Gm}$. & Tot. \% \\
\hline C 1 & .063 & .79 & .168 & 13.44 & .143 & .26 & .24 & 2.03 \\
C 2 & .088 & .94 & .17 & 10.6 & .19 & .40 & .43 & 3.16 \\
C 3 & .09 & 2.32 & .19 & 16.75 & .28 & .36 & .34 & 8.5 \\
C 4 & .18 & 1.64 & .12 & 8.7 & .18 & .475 & .26 & 3.28 \\
C 5 & .089 & .61 & .206 & 10.06 & .24 & .17 & .41 & 5.2 \\
\hline Average & .102 & 1.26 & .151 & 11.91 & .207 & .333 & .336 & 4.43 \\
\hline
\end{tabular}

radioactivity following the injection of radioactive leukocytes was then compared with the distribution in control animals, in which comparable amounts of inorganic radioactive phosphorus had been injected intravenously (Table II).

The radioactivity present in the lungs, liver, spleen, kidneys, lymph nodes, thymus, skeletal muscle, femur, skull bones and brain was determined on a percentage basis. Samples of these organs were placed in porcelain milk evaporating crucibles, dried at $100^{\circ} \mathrm{C}$. for 24 hours and then ashed in a muffle furnace for four hours at $800^{\circ}$ C. The radioactivity present was then determined in a Geiger-Mueller counter using a Geiger-Mueller bell jar, end window counting tube at a fixed geometry. Samples of a standard (composed of $1.0 \mathrm{ml}$. of the radioactive cell suspension) were used for comparison so that geometrical and decay factors were not necessary in calculating the percentage of radioactivity present. ${ }^{2}$

\section{DISTRIBUTION OF RADIOACTIVITY FOLLOWING IN-} TRAVENOUS INJECTION OF LEUKOCYTES LABELED WITH $\mathbf{P}^{32}$

\section{Results}

Rabbits sacrificed 30 minutes after the intravenous injection of leukocytes labeled with $\mathrm{P}^{32}$ were found to contain the majority of the radioactivity in the lungs. In six rabbits an average of $47.06 \%$ of the total radioactivity injected was found in the lungs as compared to $21.91 \%$ in the liver, $1.82 \%$ in the spleen, and $2.63 \%$ in the kidneys. On a per cent per gram basis the preponderance of radioactivity in the lungs was even more striking. The lungs contained an average of $3.06 \%$ of the total radioactivity injected per gram as compared to $.24 \% / \mathrm{Gm}$. in the liver, $.65 \% / \mathrm{Gm}$. in the spleen and $.15 \% / \mathrm{Gm}$. in the kidneys (Figures 1 and 2, Table III). Relatively insignificant amounts were found in the other tissues. The distribution of most of the radioactivity in the lungs following the intravenous injection of labeled leukocytes is in marked contrast to the much smaller amounts of radioactivity found in this organ when control animals were injected with inorganic radioactive phosphorus (Table IV). The amount of radioactivity in the liver and spleen was also considerably greater than that found in control rabbits, but the differences are not as marked as in the case of the lungs. The amount of radioactivity found in the kidneys of control
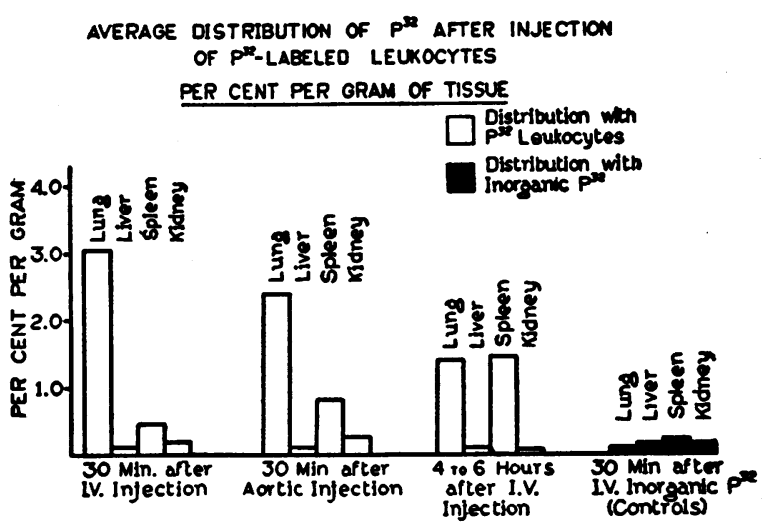

Fig. 1. The Distribution of Radionctivity in TisSUES Following InJection OF LABELED LeUrocytes Compared to Distribution of Radionctivity Following Injection of Inorganic Radionctive Phosphorus

The effect of intravenous injection is compared to the effect of aortic injection. Results in per cent per gram of tissue.

Calculations:

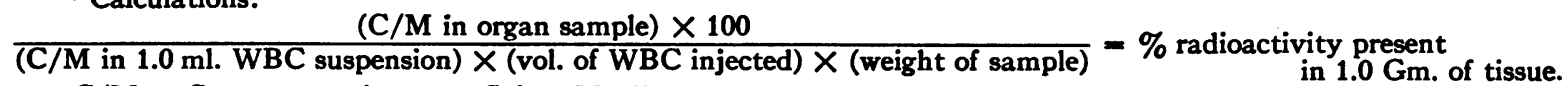

$\mathrm{C} / \mathrm{M}=$ Counts per minute on Geiger-Mueller counter. 
TABLE III

Distribution of radioactivity in tissues 30 minutes after the intravenous (ear vein) injection of leukocyites labeled with radioactive phosphorus

\begin{tabular}{|c|c|c|c|c|c|c|c|c|}
\hline \multirow{2}{*}{$\begin{array}{l}\text { Rabbit } \\
\text { number }\end{array}$} & \multicolumn{2}{|c|}{ Lung } & \multicolumn{2}{|c|}{ Liver } & \multicolumn{2}{|c|}{ Spleen } & \multicolumn{2}{|c|}{ Kidney } \\
\hline & $\% / \mathrm{Gm}$. & Tot. $\%$ & $\% / \mathrm{Gm}$. & Tot. \% & $\% / \mathrm{Gm}$ & Tot. $\%$ & $\% / \mathrm{Gm}$. & Tot. \% \\
\hline $\begin{array}{lr}\text { RP } & 1 \\
\text { RP } & 2 \\
\text { RP } & 7 \\
\text { RP } & 10 \\
\text { RP } & 14 \\
\text { RP } & \mathbf{3 0} \\
\text { RP } & \mathbf{3 1}\end{array}$ & $\begin{array}{l}2.0 \\
1.3 \\
5.2 \\
3.9 \\
2.97 \\
4.06 \\
1.95\end{array}$ & $\begin{array}{l}38.0 \\
18.98 \\
51.0 \\
62.4 \\
56.4 \\
71.7 \\
30.9\end{array}$ & $\begin{array}{l}.09 \\
.27 \\
.33 \\
.27 \\
.25 \\
.21 \\
.25\end{array}$ & $\begin{array}{l}9.10 \\
17.36 \\
34.0 \\
21.7 \\
21.0 \\
22.8 \\
27.4\end{array}$ & $\begin{array}{l}.19 \\
.19 \\
.93 \\
.35 \\
.63 \\
.40 \\
1.89\end{array}$ & $\begin{array}{l}.95 \\
5.1 \\
1.3 \\
1.26 \\
1.07 \\
.5 \\
2.61\end{array}$ & $\begin{array}{l}.11 \\
.31 \\
.10 \\
.12 \\
.13\end{array}$ & $\begin{array}{l}1.1 \\
5.0 \\
2.0 \\
\overline{2.04} \\
3.02\end{array}$ \\
\hline Average & 3.06 & 47.06 & .24 & 21.91 & .65 & 1.82 & .15 & 2.63 \\
\hline
\end{tabular}

AVERAGE DISTRIBUTION OF PE AFTER INJECTION OF P LABELED LEUKOCYTES TOTAL PER CENT PER ORGAN

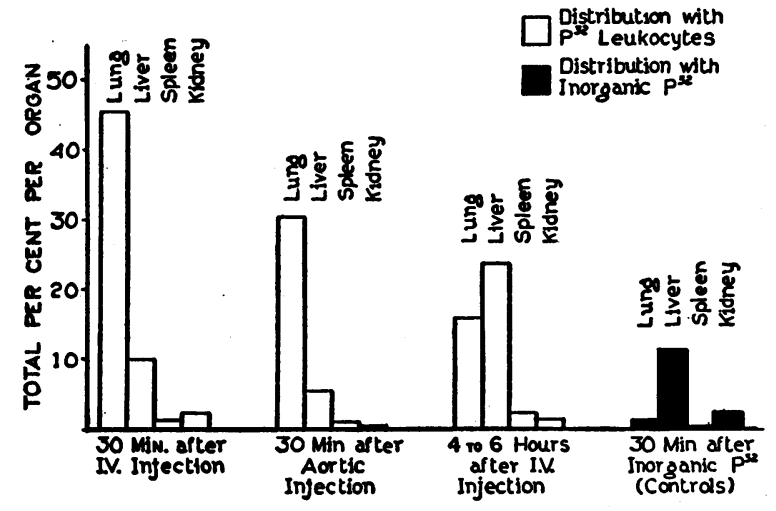

Fig. 2. The Distribution of Radioactivity in Tissues Following InJection of Labeled LeUkocytes Compared to Distribution of Radioactivity Following Injection of Inorganic Radionctive Phosphódus

The effect of intravenous injection is compared to the effect of aortic injection. Results in total per cent per organ. rabbits exceeded that found in the rabbits transfused with radioactive leukocytes.

The preponderance of radioactivity in the lungs was correlated with the histologic appearance of the lungs which showed marked engorgement of the intra-alveolar septa with leukocytes. The accumulation of leukocytes in the liver and spleen was much less marked.

When the rabbits were sacrificed four to six hours after the injection of labeled leukocytes instead of after 30 minutes a different distribution of radioactivity was found (Tables IV and V, Figures 1 and 2). In five rabbits the lung and spleen contained the most radioactivity on a per cent per gram basis, the amounts averaging $1.5 \% / \mathrm{Gm}$. and $1.58 \% / \mathrm{Gm}$. respectively. However, when the percentage per gram found in each rabbit is noted, rather than the average per cent per gram (Table V), it can be seen that with exception of one rabbit (RP 13) the radioac-

TABLE IV

Average distribution of radioactivity in tissues following injection of leukocytes labeled with radioactive phosphorus

\begin{tabular}{|c|c|c|c|c|c|c|c|c|}
\hline \multirow{2}{*}{ Site of injection } & \multicolumn{2}{|c|}{ Lung } & \multicolumn{2}{|c|}{ Liver } & \multicolumn{2}{|c|}{ Spleen } & \multicolumn{2}{|c|}{ Kidney } \\
\hline & $\% / G m$. & Tot. \% & $\% / \mathrm{Gm}$ & Tot. \% & $\% / \mathrm{Gm}$ & Tot. \% & $\% / G m$. & Tot. \% \\
\hline Control (inorganic $P$ ) & .102 & 1.26 & .151 & 11.91 & .207 & .333 & .336 & 4.43 \\
\hline $\begin{array}{l}30 \text { min. after I.V. injection of radio- } \\
\text { active WBCs }\end{array}$ & 3.06 & 47.06 & .24 & 21.91 & .65 & 1.82 & .15 & 2.63 \\
\hline $\begin{array}{l}30 \text { min. after aortic injection of radio- } \\
\text { active WBCs }\end{array}$ & 2.51 & 30.06 & .21 & 17.24 & 1.01 & 1.6 & .21 & 4.49 \\
\hline $\begin{array}{l}\text { Four to six hrs. after I.V. injection } \\
\text { of radioactive WBCs }\end{array}$ & 1.5 & 17.7 & .39 & 35.6 & 1.58 & 2.93 & .08 & 1.57 \\
\hline
\end{tabular}




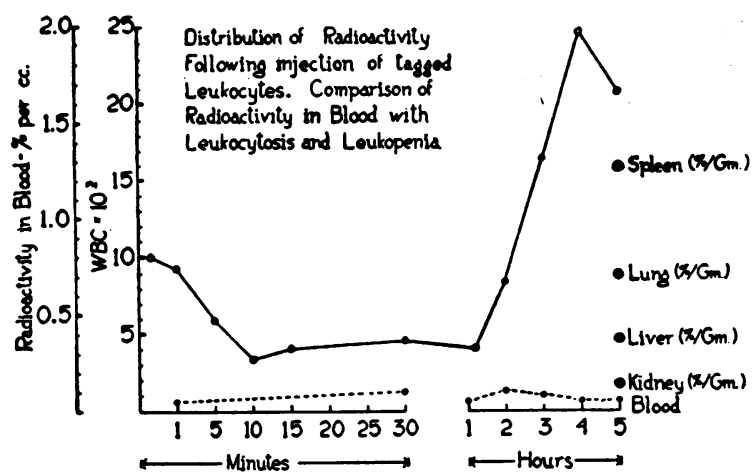

Fig. 3. Comparison of Radioactivity of Blood with Leuropenia AND Leurocytosis Following InJection of LABELEd LeUKocytes

The amount of radioactivity in the blood does not parallel the rise in white count, indicating that the labeled leukocytes probably do not re-enter the circulation at the time of leukocytosis. The dotted line at the bottom of the chart represents radioactivity in per cent per milliliter of blood. The amount of radioactivity found in the spleen, lung, liver and kidney at the end of five hours is indicated on the right.

tivity found in the spleen exceeded that in the lung. When the percentage found in the entire organ is considered the majority of radioactivity is found in the liver. The liver contained an average of $35.6 \%$ of the total radioactivity, the lungs $17.7 \%$, the spleen $2.93 \%$ and the kidneys $1.57 \%$. The other organs again contained relatively insignificant amounts.

When the amount of radioactivity in the peripheral blood was studied in conjunction with the typical appearance of leukopenia followed by leukocytosis which occurs following transfusion of concentrated suspensions of leukocytes (1), no comparable fall or rise in radioactivity was noted.
Only relatively insignificant amounts of radioactivity were found in the peripheral blood in serial determinations (Figure 3 ). This indicates that the frequently occurring subsequent leukocytosis is not the result of release of cells previously sequestered in the lung.

\section{DISTRIBUTION OF RADIOACTIVITY FOLLOWING IN- TRA-AORTIC AND INTRA-ARTERIAL INJECTION OF LEUKOCYTES LABELED WITH $\mathbf{P}^{32}$ \\ Results}

When leukocytes are injected intravenously, the first large capillary bed with which they come into contact is that of the lungs. In order to discover whether or not the sequestration of leukocytes in the lung is a specific or nonspecific capillary effect, leukocytes were transfused through the aorta, as well as the femoral and carotid arteries.

The right carotid artery was cannulated so that the tip of the cannula was pointing in the direction of the arch of the aorta. A suspension of radioactive leukocytes was then injected and flushed into the circulation with $5.0 \mathrm{ml}$. of physiologic saline. When the rabbits were sacrificed at the end of 30 minutes, the majority of the radioactivity was again found in the lungs (Tables $\mathrm{V}$ and VI, Figures 1 and 2). The lungs were found to contain an average of $30.06 \%$ of the total radioactivity injected, the liver $17.24 \%$, the spleen $1.6 \%$ and the kidneys $4.49 \%$. On a per cent per gram basis the lungs contained $2.51 \%$, the liver $.21 \%$, the spleen $1.01 \%$ and the kidneys $.21 \%$.

When the carotid artery was cannulated so that the brain was perfused before the radioactive

TABLE V

Distribution of radioactivity in tissues four to six hours following intravenous (ear vein) injection of leukocytes labeled with radioactive phosphorus

\begin{tabular}{|c|c|c|c|c|c|c|c|c|}
\hline \multirow{2}{*}{$\begin{array}{c}\text { Rabbit } \\
\text { number }\end{array}$} & \multicolumn{2}{|c|}{ Lung } & \multicolumn{2}{|c|}{ Liver } & \multicolumn{2}{|c|}{ Spleen } & \multicolumn{2}{|c|}{ Kidney } \\
\hline & $\% / \mathrm{Gm}$ & Tot. \% & $\% / \mathrm{Gm}$ & Tot. \% & $\% / \mathrm{Gm}$ & Tot. \% & $\% / \mathrm{Gm}$ & Tot. \% \\
\hline $\begin{array}{ll}\text { RP } & 9 \\
\text { RP } & 13 \\
\text { RP } & 15 \\
\text { RP } & 16 \\
\text { RP } & 32\end{array}$ & $\begin{array}{c}.84 \\
4.3 \\
.73 \\
.95 \\
.70\end{array}$ & $\begin{array}{l}9.83 \\
36.5 \\
11.7 \\
18.5 \\
11.95\end{array}$ & $\begin{array}{l}.53 \\
.50 \\
.36 \\
.23 \\
.36\end{array}$ & $\begin{array}{l}39.4 \\
35.5 \\
40.0 \\
25.0 \\
38.0\end{array}$ & $\begin{array}{l}1.62 \\
2.6 \\
1.2 \\
1.23 \\
1.26\end{array}$ & $\begin{array}{l}3.3 \\
3.9 \\
4.45 \\
1.38 \\
1.64\end{array}$ & $\begin{array}{l}.13 \\
.01 \\
.13 \\
.04 \\
.11\end{array}$ & $\begin{array}{l}2.5 \\
.13 \\
2.24 \\
.74 \\
2.26\end{array}$ \\
\hline Average & 1.5 & 17.7 & .39 & 35.6 & 1.58 & 2.93 & .08 & 1.57 \\
\hline
\end{tabular}


TABLE VI

Distribution of radioactivity in tissues 30 minutes after injection of leukocytes labeled with radioactive phosphorus into the aorta

\begin{tabular}{c|c|c|c|c|c|c|c|c}
\hline \hline \multirow{2}{*}{$\begin{array}{c}\text { Rabbit } \\
\text { number }\end{array}$} & \multicolumn{2}{|c|}{ Lung } & \multicolumn{2}{c|}{ Liver } & \multicolumn{2}{c|}{ Spleen } & \multicolumn{2}{c}{ Kidney } \\
\cline { 2 - 9 } & $\% / \mathrm{Gm}$. & Tot. \% & \%/Gm. & Tot. \% & $\% / \mathrm{Gm}$. & Tot. \% & $\% / \mathrm{Gm}$. & Tot. \% \\
\hline RP 23 & 1.45 & 28.8 & .36 & 25.0 & .42 & .40 & .38 & 7.9 \\
RP 26 & 2.30 & 27.0 & .17 & 18.2 & .33 & .18 & .21 & 4.4 \\
RP 27 & 3.20 & 40.05 & .19 & 15.3 & .33 & .29 & .25 & 3.35 \\
RP 28 & 3.25 & 26.0 & .17 & 12.7 & .84 & .55 & .25 & 4.00 \\
RP 29 & 2.35 & 31.1 & .19 & 15.01 & 4.16 & 6.57 & .16 & 2.78 \\
\hline Average & 2.51 & 30.06 & .21 & 17.24 & 1.01 & 1.6 & .21 & 4.49 \\
\hline
\end{tabular}

leukocytes entered the lesser circulation, no increase in the amount of radioactivity present in the brain was found in two rabbits. The majority of the radioactivity was found in the lungs.

When radioactive leukocytes were injected into the cannulated femoral artery, no significant increase in the amount of radioactivity present in the muscles supplied by the artery was found. In two rabbits, however, slightly more radioactivity was found in the muscles of the leg supplied by the artery into which the leukocytes were injected than was found in the muscles of the contralateral leg. The majority of the radioactivity was again present in the lungs.

\section{DISCUSSION}

It is evident that under the conditions of these experiments transfused white cells do not remain in the peripheral blood stream and that sequestration in the lungs is a major factor in removing them from the circulation. The specific action of the lungs in this mechanism is demonstrated by the marked accumulation of radioactivity in the lungs when labeled leukocytes are injected into the systemic circulation via the arterial as well as the venous system. This is further corroborated by the marked engorgement of the lung capillaries with leukocytes which was demonstrated in histologic sections. The selective action of the lungs in removing transfused leukocytes despite the injection into various arteries and veins as well as the aorta indicates that the mechanism involved is more than a nonspecific capillary sequestration which might occur in the first capillary bed encountered by the transfused leukocytes.

Sequestration of leukocytes in the liver and spleen during the first 30 minutes after the trans- fusion of leukocytes is much less marked than in the lung. The function of the peripheral capillaries in this respect is negligible. The part played by the lung is even more striking when it is considered that the lungs contained an average of $47.06 \%$ of the total radioactivity as compared with an average of $21.91 \%$ in the liver, even though the liver usually weighs five or more times as much as the lung.

The shift of radioactivity away from the lungs to the liver and spleen after four to six hours probably indicates destruction of the transfused leukocytes, but may represent migration of intact leukocytes. It seems unlikely that the transfused cells subsequently reappear in the circulation in appreciable numbers since there is no change in the radioactivity of the peripheral blood (Figure 3).

While no blood cell removed from the body can be considered to be entirely normal, the leukocytes used here retained normal staining reactions, normal motility and normal phagocytic activity. It seems reasonable to assume that they are as nearly normal as the leukocytes of stored blood regularly used in transfusions of human patients. The possibility exists, therefore, that the mechanism of removal of leukocytes described here also accounts for the failure to elevate the leukocyte count of patients with blood transfusions.

\section{SUMMARY AND CONCLUSIONS}

1. The fate of transfused leukocytes was studied by determining the distribution of radioactivity in various tissues of the body following the injection of leukocytes labeled with $\mathrm{P}^{32}$.

2. In rabbits sacrificed 30 minutes after the intravenous injection of radioactive leukocytes, by 
far the majority of the radioactivity was found in the lungs. The marked accumulation of radioactivity in the lungs also occurred when the radioactive leukocytes were transfused via the aorta as well as the femoral and carotid arteries. The accumulation of radioactivity in the lungs was correlated with the histologic demonstration of engorgement of the intra-alveolar septa of the lungs with leukocytes.

3. In rabbits sacrificed four to six hours after the injection of radioactive leukocytes the majority of the radioactivity was found in the spleen and lung on a per cent per gram basis. On a total organ basis, however, the liver contained the majority of the radioactivity. This shift of radioactivity away from the lungs is probably due to destruction of the transfused leukocytes but may be due to migration of intact leukocytes with transfer of the radioactive phosphorus to the liver.

4. Under the conditions of these experiments, the lungs play the major role in the prompt removal of transfused leukocytes from the peripheral blood. The liver and spleen also contribute to the rapid disappearance of the transfused cells but not to the same extent as the lung. The role of the peripheral capillaries in this mechanism is negligible.

5. That the removal of the transfused white cells is more than a mere filtration of foreign bodies by the reticulo-endothelial system is indicated by the selective action of the lungs in removing cells transfused into the arterial as well as the venous system.

\section{BIBLIOGRAPHY}

1. Weisberger, A. S., Heinle, R. W., and Hannah, R., Transfusion of leukocytes and products of disintegrated leukocytes. Proc. Soc. Exper. Biol. \& Med., 1949, 70, 749.

2. Mudd, S., Lucké, B., McCutcheon, M., and Strumia, M., On the mechanism of opsonin and bacteriotropin action; correlation between changes in bacterial surface properties and in phagocytosis caused by sera of animals under immunization. J. Exper. Med., 1929, 49, 779. 